\title{
Isolation of Infectious Bronchitis Virus in Primary cells of the Chick Embryo Chorioallantoic Membrane
}

\author{
M.H. Mohammed ${ }^{1 @}$; M. Hair-Bejo ${ }^{1}$; Abdel Ameer Husain Zahid²; Amer Alazawy³; \\ Emad Adwar Abdul Ahad ${ }^{4}$ and Mauida F. Hasoon ${ }^{1}$ \\ ${ }^{1}$ Faculty of Veterinary Medicine, Universiti Putra Malaysia, Selangor, Malaysia; ${ }^{2}$ College of Veterinary \\ Medicine, Baghdad University, Iraq; ${ }^{3}$ College of Veterinary Medicine, Diyala University, Iraq; ${ }^{4}$ College of \\ Veterinary Medicine, Sulaimania University, Sulaimania, Iraq. \\ majed_mohammed@putra.upm.edu.my \\ Accepted on 5/12/2012
}

\section{Summary}

The susceptibility of the primary chick embryo chorioallontoic membrane cells to infectious bronchitis virus was evaluated after twenty consecutive passages in chick embryo chorioallontoic membrane cells. Virus replication was monitored by cytopathic observation, indirect immunoperoxidase, and reverse transcription polymerase chain reaction (RT-PCR). At 72 hours post-infection in third passage, the cytopathic effect was characterized by rounding up of cells, monolayer detachment, intracytoplasmic brownish colouration was readily observed by immunoperoxidase from 24hours p.i in third passage, and at all times the extracted viral RNA from IBV-infected monolayers was demonstrated by RT-PCR. Tissue culture ineffective dose ${ }_{50}\left(\mathrm{TCID}_{50}\right)$ was used to measure virus titration performed on primary chick embryo chorioallontoic membrane cells and the titre in twenty passage was $10^{8.6} \mathrm{TCID}_{50} / \mathrm{ml}$.

The results obtained in this study suggested that the primary chick embryo chorioallontoic membrane cells can be used for adaptation infectious bronchitis virus (IBV) and may be considered a step forward for the use of these cells in the future for IBV vaccine production

Keywords: IBV, Chick, Chorioallantoic, isolation, Chick embryo.

Introduction

Infectious bronchitis virus (IBV) infects the respiratory tract, kidneys and oviduct of chickens of all ages, causing retarded growth, mortality, reduced egg production and inferior egg shell quality and in many countries the disease remains one of the main problems affecting existing or developing poultry industries. Until now, there is no cure for the disease (1). Prevention is to import birds from disease-free flocks only or through vaccination, broilers are normally vaccinated at 1 day of age with live attenuated vaccines (2). In addition, breeders and egg layers are also vaccinated at approximately 8 week intervals with live attenuated vaccines, and with inactivated vaccines after they start laying eggs (3). Acute Infectious bronchitis virus are usually detected by the indirect immunoperoxidase test, enzymelinked immunosorbent assay, virus isolation or serological approaches (4 and 5). However IBV infections can also be diagnosed by detection of viral RNA by RT-PCR, which make the diagnostic rapid, and also dependable (6 and 7).
Infectious bronchitis vaccines have been produced by growing vaccine virus strains in embryonated chicken eggs. IBV is harvested from the allantoic fluid and used to create a vaccine; nevertheless this method has the disadvantages of being labour-dense, takes long time and requires large area for the incubation of eggs. Cell cultures considered are more suitable and less expensive than eggs and also convenient to inspect microscopically for indication of viral proliferation (5 and 8). There is therefore an urgent need to improve on the current IBV vaccines production technologies based chick embryo chorioallontoic membrane (CAM) cells. The development of cell-culture platforms as an alternative to the eggs for the manufacture of IBV vaccines is likely the most rapid and promising solution to overcome current vaccines production. This study aimed to, investigat the ability of IBV to grow in chorioallontoic membrane cells and second to detect titres of IBV in chorioallontoic membrane cells plus the possibility to use these cells for vaccine production in the future. 


\section{Materials and Methods}

The stock of IBV was originally obtained from the Faculty of Veterinary Medicine / University Putra Malaysia This virus was isolated from the allantoic fluid of embryonated chicken eggs. Initially, $0.3 \mathrm{ml}$ of the virus stock was diluted in $30 \mathrm{ml}$ of 10x PBS giving a dilution of $1: 100$. This diluted virus was used to inoculate primary chick embryo chorioallontoic membrane cells. Fully confluent $25 \mathrm{~cm}^{2}$ flasks of cells were used for virus passage in an attempt to adapt the virus to replicate in these cells.

Primary chick embryo chorioallontoic membrane (CAM) cells were prepared from 9 to 10 days old specific pathogenic free (SPF) chick embryo. The chorioallontoic membranes were collected, washed with phosphate buffer saline and digested with trypsin/EDTA. The reaction was stopped by adding (Dulbecco's Minimal109 Essential Medium (DMEM) complete growth medium (GIBCO Laboratories, USA) supplement with; $2.0 \mathrm{~g}$ NaHCo3, 10\% fetal calf serum (FCS) and 1\% antibiotic of penicillin-streptomycin. After centrifugation at $1000 \mathrm{~g}$ for $10 \mathrm{~min}$, the chorioallontoic membrane cells were resuspended in the same medium and filtered through sterile gauze. The chorioallontoic membrane cells in the filtrate were distributed on plastic tissue culture flasks and incubated at $37{ }^{\circ} \mathrm{C}$ with $5 \% \mathrm{CO} 2$.

Tissue culture infective dose $50\left(\mathrm{TCID}_{50}\right)$ : The infectivity of replicate infectious bronchitis virus to chorioallontoic membrane cells were determined by calculating $50 \%$ end point, as described by researchers (9). Ten-fold serial dilution of IBV was prepared in phosphate buffer saline phosphate buffer saline from $10^{-1}$ to $10^{-10}$. A 96 well tissue culture microtiteration plate (Titertek, UK) was used to prepare chorioallontoic membrane cells monolayers. A $100 \mu \mathrm{l}$ of each virus dilution was added in each well of first row leaving last two wells as negative control. The plate was incubated at $37^{\circ} \mathrm{C}$ for 1 hour to allow adsorption. Then $100 \mu \mathrm{l}$ of prewarmed maintenance medium was added in each well and again incubated at $37^{\circ} \mathrm{C}$ in $5 \% \mathrm{CO}_{2}$. Plate was observed twice daily for CPEs. The cells were stained with $1 \%$ crystal violet solution to determine the CPE. The highest dilution of virus showing 50\% CPEs was considered as end point to calculate $\mathrm{TCID}_{50} / \mathrm{ml}$.

The indirect immunoperoxidase test (IIP) was done according to the method of workers (4). The infected chorioallontoic membrane cells were fixed with cold methanol: acetone (50:50 volum/volum) for 5 mins. The glass slides were then immersed in $1 \%$ hydrogen peroxide in absolute methanol for 30 mins. The phosphate puffer salain was then added to the glass slide for 15 mins. The glass slides were then air dried. The hyper immune serum was diluted 1:1000 with PBS and added to the glass slide incubated for 1 hour in room temperature. The glass slides were then washed 3 times with phosphate puffer saline for 5 mins each. The rabbit anti-chicken IgG-HRP conjugated secondary antibody (Bio-Rad, USA) was then added to the glass slides $(1: 1000)$ and incubated for 1 hour at room temperature. DAB substrate solution (DAB reagent set, Invitrogen, USA) was then added to the glass slides and incubated for 10 minutes in a dark room. The slides were mounted with buffer glycerol and examined under light microscope.

RNA was isolated from infected cells using commercial RNeasy Mini Kit (Qiagen, USA) as recommended by the supplier. Reverse transcription polymerase chain reaction (RTPCR): For RT-PCR the infected monolayers were submitted to detect IBV replication, the partial spike (S1) gene (1025 nucleotides) of IBV was amplified RT-PCR after different passages according to the manufacturer's recommendation (Takara). The specific primers for IBV S1 gene were designed according to IBV H52 sequence (accession number AF3523151) as follows: forward, 5CTATGTAGTGCTGTTTTG-3 (nucleotides 42 to 59); reverse, 5-CCTTGAAGAGG ACCGTAA-3 (nucleotides 1049 to 1066), and the RT-PCR was run $30 \mathrm{~min}$ at $50^{\circ} \mathrm{C}$ and $2 \mathrm{~min}$ at $94^{\circ} \mathrm{C}$ for one cycle, then 30 cycles of $30 \mathrm{sec}$ at $94^{\circ} \mathrm{C}, 30 \mathrm{sec}$ at $55^{\circ} \mathrm{C}, 1.5 \mathrm{~min}$ at $72^{\circ} \mathrm{C}$, followed by $15 \mathrm{~min}$ at $72^{\circ} \mathrm{C}$ (PTC-100TM Programmable Thermal Controller; MJ Research, Inc.) (6). 
Detection of PCR products: PCR products were separated in $1.5 \%$ agarose gel in $1 \mathrm{x}$ TAE buffer stained with ethidium bromide, compared with molecular mass marker and visualized by ultraviolet (UV) transillumination.

\section{Results and Discussion}

Infected cell monolayer steadily became broken as the virus proliferates to occupy extra cells in culture. In the first and second passage, the infectivity was sluggish and not very clear as the virus was just begin to adapt on cells. Through the third passage, were able to visualize cytopathic effect but it was not whole (localized) the cells. During the fourth and fifth passage, cytopathic effect was rapid and detached in two days. It was characterised by rounding of cells, failure of cell adhesion, vacuolization in cells, clustering of infected cells (Figure, $1 \mathrm{~A}$ and B).

Infectious bronchitis (IB) virus, early described in 1930 (10), continues to be a main cause of disease in chickens of all ages and types in all parts of the world (11and12). The disease is occurring in all countries with a concentrated poultry industry, with the occurrence of infection was almost $100 \%$ in most locations (13). Most of the countries rearing poultry commercially rely on vaccination to control $\mathrm{IB}$, but the vaccine is still a great challenge for these countries because of the wide variety serotypes for this virus.

A large majority of the vaccines available are chick embryo-adapted vaccines. Cell cultures provide a useful alternative system for the virus preparation and adaptation, and find a suitable cell culture for IBV (14). In the present study, attempts were made to adaptation IBV isolate by blind passage first in SPF embryos (15) and then adapted to the CAM cells until $20^{\text {th }}$ passages. The cytopathic effects (CPEs) appeared after 72 hours of infection in third passage and this observation was also noticed by others (16), but slightly varied from findings of researchers (12) where the IBV was adapted to Vero cell line after the third passage.

The difference might be due to the cell culture passage level of the virus strains used or variation in sensitivity of cell culture to different strains.
The infectivity titre of the virus was found to increases gradually from the 5 th to the $20^{\text {th }}$ passage. The $\mathrm{TCID}_{50}$ titre was 8.6 after 20 passages (Table,1).

\section{Table,1: Virus titre determined by Tissue} Culture Infective Dose $_{50}$ (TCID $_{50}$ )

\begin{tabular}{|cc|}
\hline $\begin{array}{c}\text { Virus category and } \\
\text { passage level } \\
\text { Virulent-un adapted }\end{array}$ & Virus titre $\mathrm{TCID}_{50} / \mathrm{ml}$ \\
\hline $\mathbf{5}$ & - \\
\hline 10 & $\mathbf{6 . 5}$ \\
\hline 15 & $\mathbf{7 . 4}$ \\
\hline 20 & $\mathbf{8}$ \\
\hline
\end{tabular}

In IIPS, brown complexes were seen as brownish intracytoplasmic granules around the nucleus (Figure,2) in infected chick chorioallontoic membrane cells cultures treated with IBV antiserum, but such effects was not seen in control cell cultures.

The total infectious titre passage 20 was found to be $10^{8.6} \mathrm{TCID}{ }_{50} / \mathrm{mL}$. These finding supports the previous report by (17) as they found titre $10^{9} \mathrm{TCID}_{50} / \mathrm{mL}$ in passage 25 in Vero cells. The classical method of detecting adaptation and replication of IB virus in the cell culture using the cytopathic effect was augmented in this study with indirect immunoperoxidase is a relatively inexpensive and rapid method (18). Monoclonal antibody (Mab) reacting only with one or small number of epitopes of the IBV antigen, results in viral antigen was observed as brownish intracytoplasmic granules in CAM cells (18).

RT-PCR of different passages at passages 2, $5,10,15$ and 20 were performed. The expected 1025 bp was obtained for each passage examined (Figure,3).

RT-PCR has been used widely as a rapid, sensitive, specific, and high throughput methodology for fast detection of genetic materials. This method was used successfully for detection of IBV (6and7). In this study RTPCR performed for viral RNA extracted from infected CAM cells to amplify of $1025 \mathrm{bp}$. The use of this technique for virus detection has been reported previously (4).

In conclusion of this study that CAM cells have used for the first time to isolate and adapt IBV successfully which could open new 
horizons to use these cells for the vaccine production in the future.
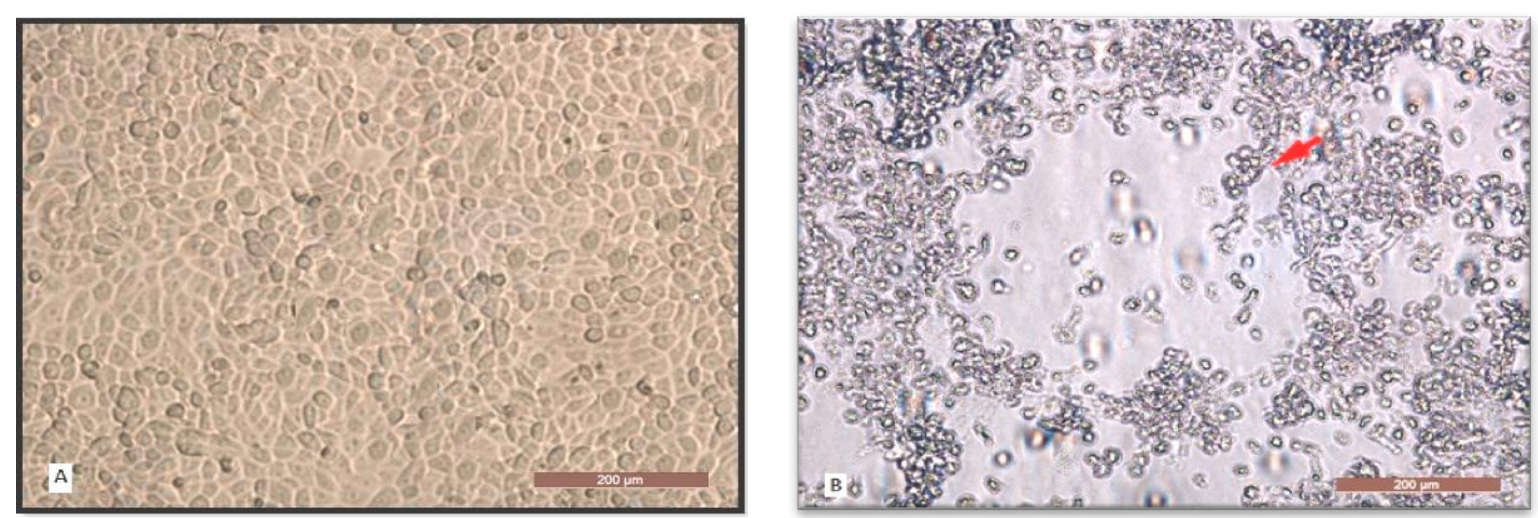

Figure, 1: (A) Uninfected control CAM cells monolayer. (B) Cytopathic effect of IBV isolate of the $3^{\text {rd }}$ passage at day 5 pi. The arrows show detachment of cells from the substrate with the eventual destruction of the entire monolayer. $10 \mathrm{x}$. Bar $=200 \mu \mathrm{m}$
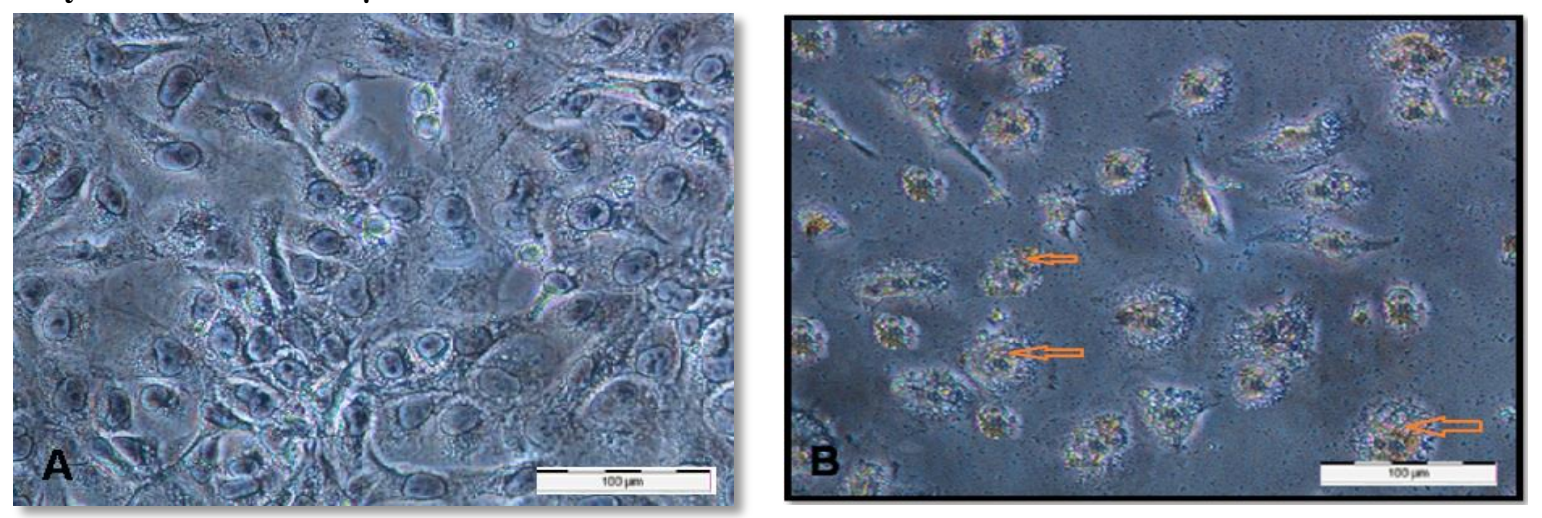

Figure, 2: Identification of IBV in CAM cells culture using infected cell cultures stained with HRP-conjugated antibody. (A) Uninfected control CAM cells. (B) CAM cells infected with IBV at $3^{\text {rd }}$ passage at day 5 pi. The arrow shows the presence of specific intracytoplasmic brownish coloration IBV antigens. 10x. Bar = 100

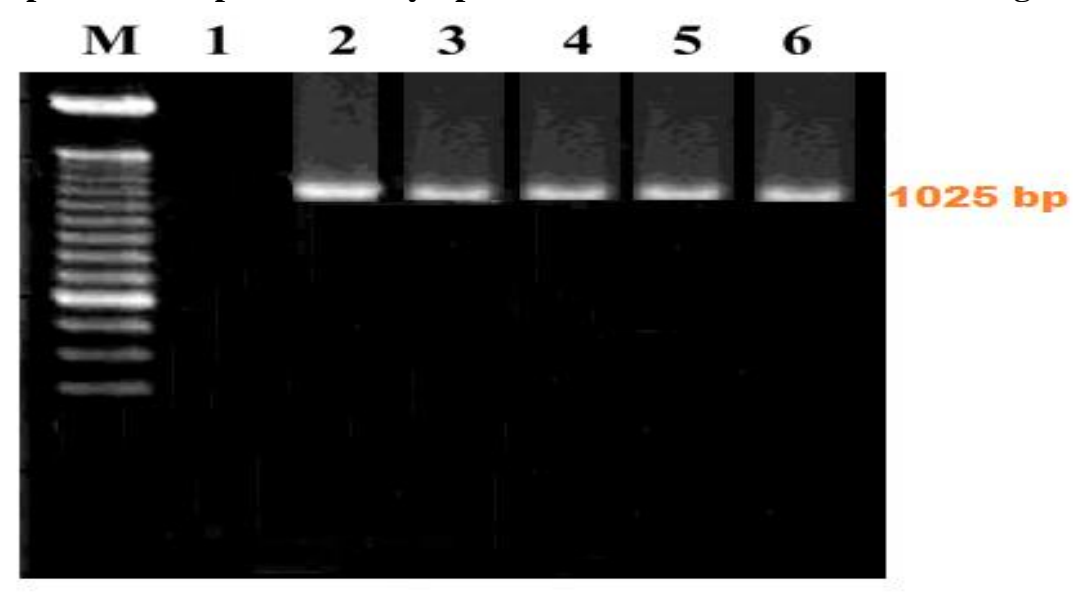

$\mu \mathbf{m}$

Figure, 3: S1 gene (1025 pb) of IBV. Lane 1 Negative control; Lane 2 positive passage 2; Lane 3 positive passage 5: Lane 4 passage 10; Lane 5 positive passage 15 and Lane 6 positive passage 20 ; M- 100 bp DNA marker (Promega, USA).

\section{Acknowledgment}

This project was supported by RUGS, Universiti Putra Malaysia (Grant no 91091). 


\section{References}

1. Office international des Epizootics (OIE) (1996). Avian infectious bronchitis, chapter 3.6.6. In Manual of standards for diagnostic test and vaccines, $3^{\text {rd }}$ Ed. OIE, Paris, PP: 539- 548.

2. Cavanagh, D. and Naqi, S.A. (1997). Infectious bronchitis. In B.W. Calnek, H.J. Barnes, C.W. Bearol, L.R. Mc Daugald, and Y.M. Saif (eds). Disease of Poultry $10^{\text {th }}$ Ed. Iawa University Press: Ames, IA., PP: 511-526.

3. Cook, J.K.; Orbell, S.J.; Woods, M.A. and Huggins, M.B. (1999). Breadth of protection of respiratory tract provided by different live attenuated infectious bronchitis vaccines against challenge with infectious bronchitis viruses of heterologous serotypes. Avian Pathol., 28: 477 - 485.

4. De Wit, J.J. (2000). Detection of infectious bronchitis virus. Avian Path., 29:71 - 93.

5. De Wit, J.J.; Mekkes, D.R.; Kouwenhoven, B. and Verheiden, J.H. (1997). Sensitivity and specificity of serological tests for infectious bronchitis virus antibodies in broilers. Avian Path., 26: 105 - 118.

6. Capua, I.; Minta, Z.; Karpinska, E.; Mawditt, K.; Britton, P.; Cavanagh, D. and Gough, R.E. (1999). Co-circulation of four types of infectious bronchitis virus (793/B, 624/I, B1648 and Massachusetts). Avian Path., 28:587 593.

7. Cavanagh, D.; Mawditt, K.; Sharma, M.; Drury, S.E.; Ainsworth, H.L.; Britton, P. and Gough, R.E. (2001). Detection of a coronavirus from turkey poults in Europe genetically related to infectious bronchitis virus of chickens. Avian Path., 30:365 378.

8. Dhinakar, G.R. and Jones, R.C. (1997). Infectious bronchitis virus: immune pathogenesis of infection in the Chicken. Avian Path., 26: 677-706.
9. Reed, L. J. and Muench, H. (1938). A simple method for estimating fifty percent end points. Am. J. Hygiene, 27: 493-497.

10. Schalk, A.F. and Hawn, M.C. (1931). An apparently new respiratory disease of chicks. J. Am. Vet. Med. Assoc., 78: 413422.

11. Anon, R. (1991). Proceedings of the Second International Symposium on Infectious Bronchitis, Rouischholzhausen Germany. P: 96.

12. Mahgoub, K.M.; Bassiouni, A.A.; Manal, A. and Afify, N.R. (2010). The prevalence of infectious bronchitis (IB) outbreaks in some chicken farms. I. Spotlight on the status of IB outbreaks in some chicken flocks. J. Am. Sci., 6(9): 57-70.

13. Ignjatovic, J. and Sapats, S. (2000). Avian infectious bronchitis virus. Rev. Sci. Off. Int. Epiz., 19: 493-508.

14. Myint, S.H., (1994). Human corona virus: a brief review. Med. Virology, 4:35-46.

15. Gelb, J., and Jackwood, M.K. (1998). Infectious bronchitis. In: A laboratory manual for the Isolation and Identification of Avian Pathogens. $4^{\text {th }}$ Ed. AAAP, PP: 169-174.

16. Hopkins, S.R. (1974). Serological comparisons of strains of infectious bronchitis virus using plaque purified isolates. Avian Dis., 18: 231-239.

17. Otsuki, K.; Noro, K.; Yamamoto, H. and Tsubokura, M. (1979). Studies on avian bronchitis virus (IBV). Propagation of IBV in several cultured cells. Arch. Vir., 60: $115-122$.

18. Arshad, S.S. and Al-Salihi, K.A. (2002). Immunohistochemical detection of infectious bronchitis virus antigen in chicken respiratory and kidney tissues. In: The Proceeding: $12^{\text {th }}$ Federation of ASIAN Vet. Assoc. Cong., 26-28 August, P: 51. 


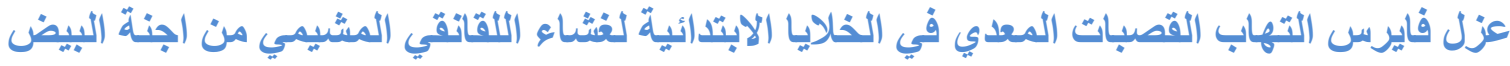

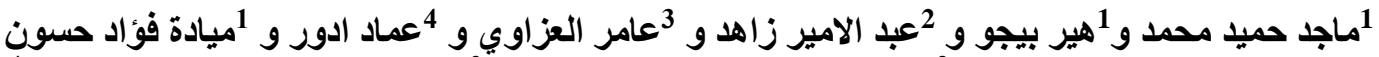

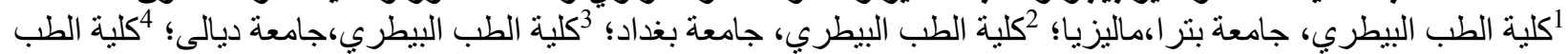

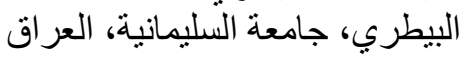

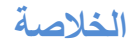

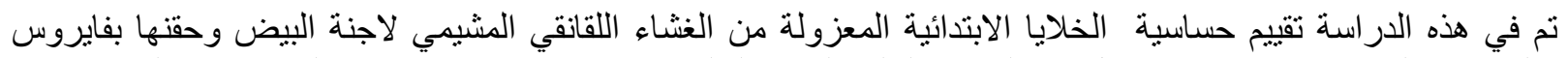

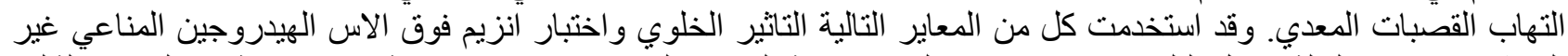

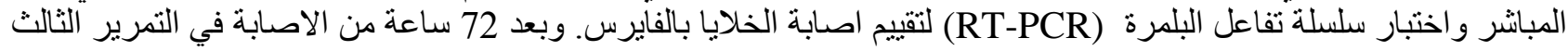

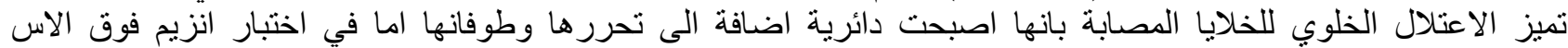

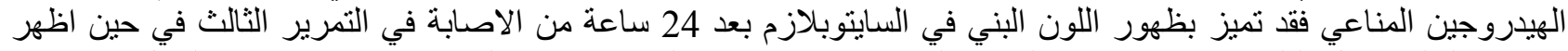

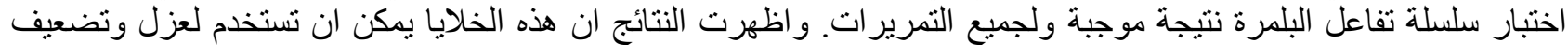
الفايروس كما يمكن ان تستخدم في تحضير اللقاح في المستقبل.

الكلمات المفتاحية: فايروس التهاب القصبة المعدي، الفثاء اللقانقي المشيمي، العزل راجنة البيض. 